\title{
On a possible mechanism of Alpine debris flows
}

\author{
G. Breitfuss - A. E. ScheidegGer $(*)$
}

Received on December 7th, 1973

Summary. - The phenomenology and previous mechanical theories of Alpine debris flows are reviewed. A new model for the mechanics of such debris flows is proposed which is based on the notion of dispersive pressure occurring in shear flows introduced by Bagnold. It is shown that the values of the dynamical variables required by this model are of the order of magnitude of those observed in nature.

Riassunto. - Dopo aver passato in rassegna e riesaminato la fenomenologia e le precedenti teorie meccaniche sul trasporto di detriti Alpini, gli A.A. propongono un nuovo modello per la meccanica di tale trasporto basato sul concetto di pressione dispersiva introdotto da Bagnold.

Viene dimostrato che i valori delle variabili dinamiche richiesti da questo modello sono dell'ordine di grandezza di quelli osservati in natura.

\section{1. - Phenomenology}

Alpine debris flows (in German "Murgang") are mixtures of water, fine materials, sand, gravel, large blocks and pieces of vegetation which move downstream with great velocity in an existing river channel. They develop only under special conditions after particularly severe rainstorms. A region may be spared the experience of a debris flow for a hundred years or so, then suddenly an ordinarily tame mountain streamlet becomes "activated" by such a flow and causes great damage. Individual debris flows have been described on many occasions starting with Stiny $\left(^{5}\right)$ in 1910 . The present writers also had the opportunity to inspect several debris flows themselves.

(*) Institut für Geophysik, Technische Hochschule, Wien, Austria. 
Thus, a typical profile of a mountain stream prone to conducting debris flows consists of three regions: a region where the debris material is collected, a region where it moves downhill in a gorge, and a region where it is deposited in form of an alluvial blanket. As an example, we show here the drainage area of the Dürnbach in the Pinzgau in Austria (Fig. 1) and the corresponding profile (Fig. 2).

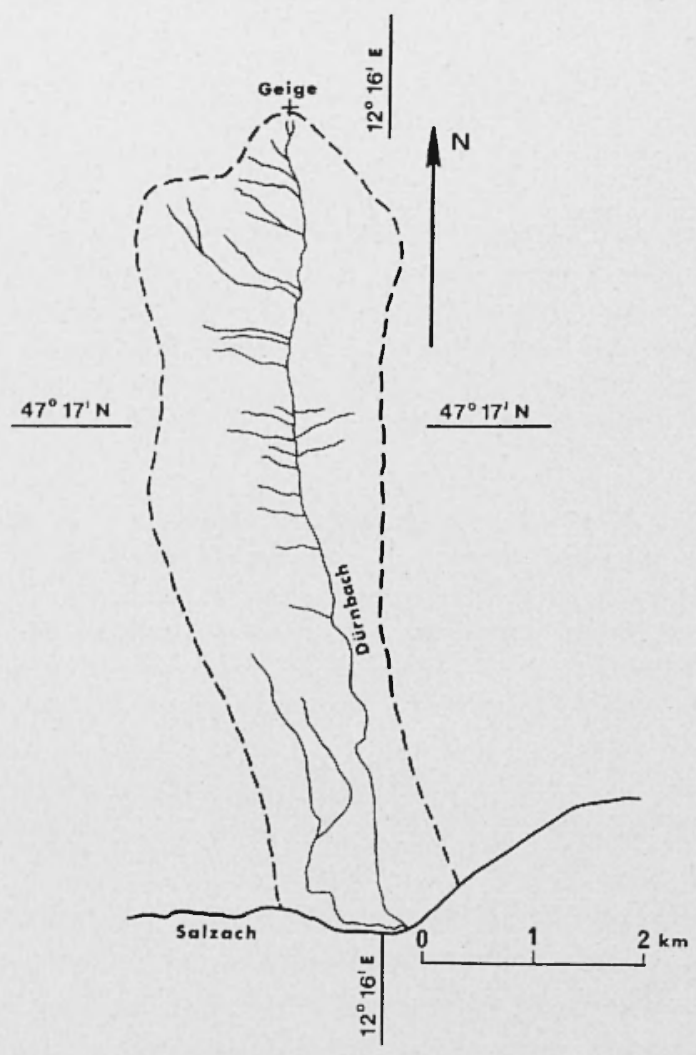

Fig. 1 - Drainage area of a typical mountain stream prone to debris flows (Dürnbach in the Pinzgau in Austria).

Similar conditions are found in other cases. Thus, the region where the material is collected, is usually formed by steep Alpine meadows intersected by single rock spurs ending in a gentle bottom; unstable slide areas contribute the debris material (Fig. 3). The gorge area is narrow and steep (Fig. 4), the area of deposition is generally conical 
(alluvial cone) where successive "blankets" of debris are deposited by the individual debris flows (Fig. 5).

The total amount of material transported in a single debris flow may exceed $100,000 \mathrm{~m}^{3}\left({ }^{3}\right)$. The velocity is of the order of several $\mathrm{m} / \mathrm{sec}$ and may reach $20 \mathrm{~m} / \mathrm{sec}$ after overcoming an obstacle $\left(^{5,3,1}\right)$. The concentration of solids transported in the water has been estimated as 50-80 per cent. of volume. The bulk density of the debris flow

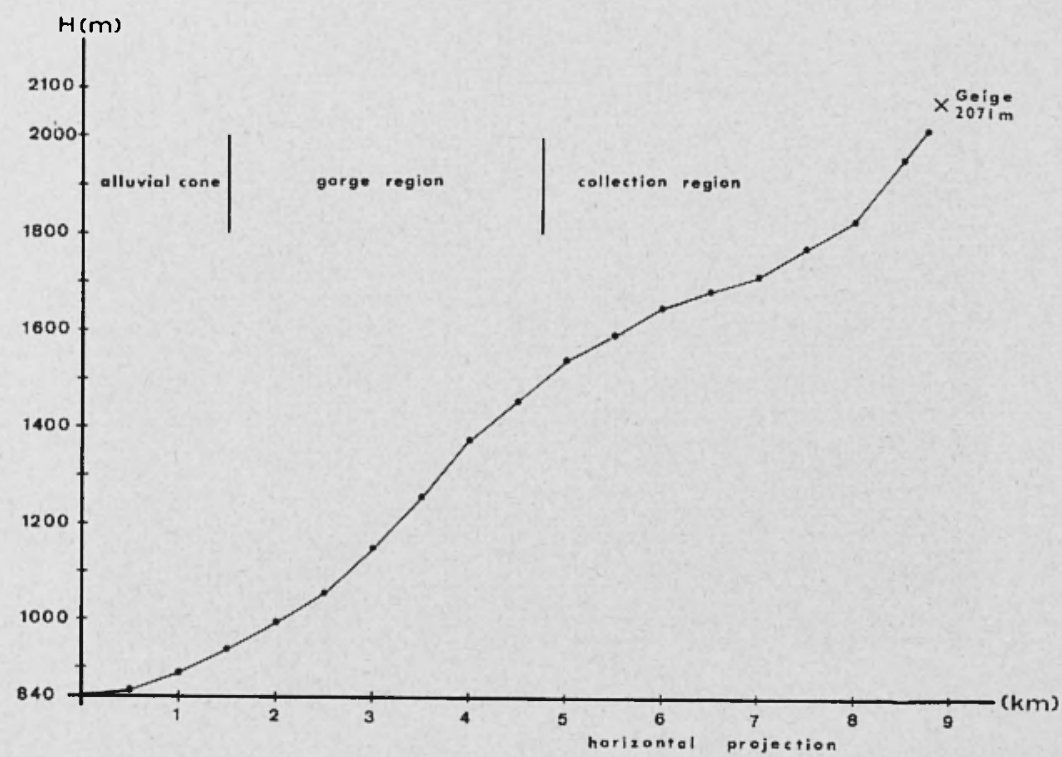

Fig. 2 - Profile of the course of a mountain stream prone to debris flows (Dürnbach in the Pinzgau in Austria).

during motion is thus about $2.6 \mathrm{~g} / \mathrm{cm}^{3}$. The grain size distribution reaches from the finest of materials to rocks several meters in diameter. The material in the deposited blankets is barely or not at all graded; large blocks are usually embedded in fine materials. The orientation of the debris, however, is preferentially with the largest diameter of the individual grains (blocks) in the direction of the flow.

\section{2. - Previous Theories}

The theories purporting to explain the mechanics of debris flows have generally been based upon analogies with bed load transport 
in rivers. $\Lambda$ review of these theories has been given by Scheidegger ( $\left.{ }^{4}\right)$. However, it should be noted that it is somewhat doubtful that such analogies are pertinent for $A$ lpine debris flows, inasmuch as bed load transport appears to be primarily a drag phenomenon whereas Alpine debris flows seem to represent the movement of the mixture of solids and water by itself.

Thus, an analogy with turbidity currents at sea or powder snow avalanches rather than one with bed load transport may therefore

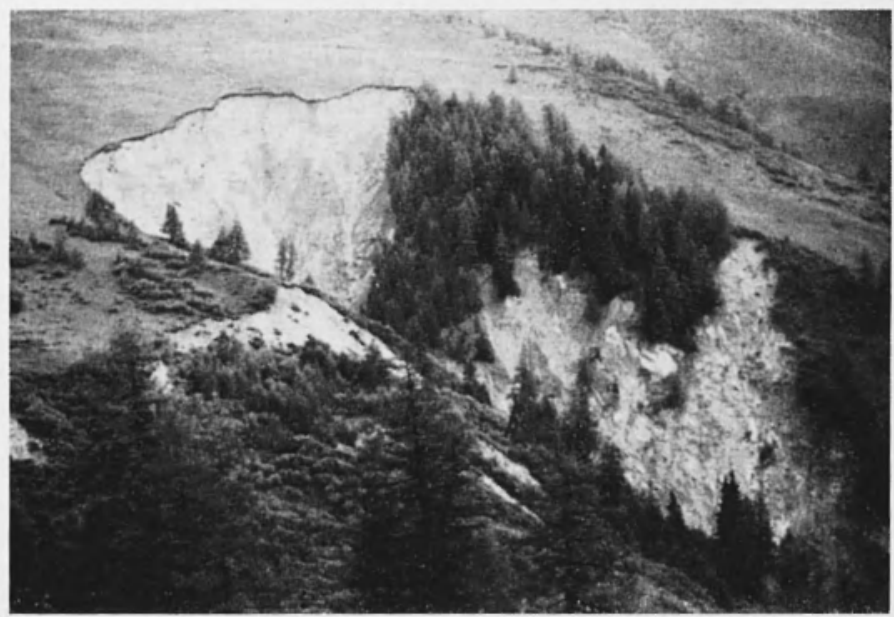

Figr. 3 - Unstable slide area in the collection regrion of a mountain stream prone to debris flows (Raseck Bach in Eastern Tyrol, Austria).

be more pertinent for Alpine debris flows. However, such analogies presuppose a rather low density of the solid material inasmuch as it is sustained turbulence of the carrying medium which keeps the solids in suspension.

Evidently, the mechanism of debris flows must be somehow intermediate between bed drag and suspension. A mechanism that has been but little explored in this connection is the motion of fluidized solids.

\section{3. - Bagnold's Dispersive Pressure}

A type of fluidization mechanism that may be operative in Alpine debris flows was described by Bagnold (2). Thus, assume that a dis- 
persion of spheres is being sheared (Fig. 6). Under these conditions, a "dispersive pressure" will become operative normal to the shearing direction because of the collisions between the grains (inertial regime)

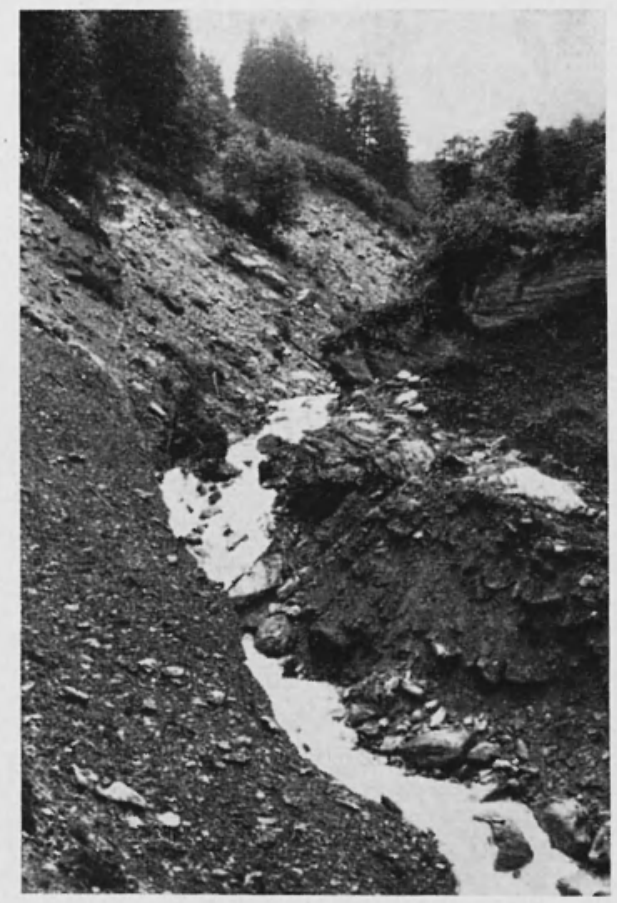

Fig. 4 - Gorge region of a mountain stream prone to debris flows (Niedernsiller Muhlbach in the Pinzgau, Austria).

or because of the influence of the grains on the flow patterns of the fluid around neighbouring grains (macroviscous regime).

In the inertial regime, this pressure $P$ is

$$
P=a_{i} \sigma \lambda f(\lambda) D^{2}(\mathrm{~d} U / \mathrm{d} y)^{2} \cos \alpha
$$

where $\sigma$ is the density of the grains, $D$ their diameter, and $\mathrm{d} U / \mathrm{d} y$ is the shearing velocity. The quantity $\lambda$ is a measure of concentration

$$
\lambda=\frac{1}{\left(c_{o} / c\right)^{1 / 3}-1}
$$


where $c$ is the actual and $c_{o}$ the maximum possible volume concentration of the grains (for spheres $c_{0}=0.74$ corresponding to hexagonal packing). Furthermore, al is an empirical constant, $f(\lambda)$ is an empirical function and $\alpha$ is the angle between the dispersive pressure $P$ and the force $F$ resulting from the collisions between grains (cf. Fig. 6). Correspondingly, the shearing force $T$ experienced is

$$
T=P \tan \alpha
$$

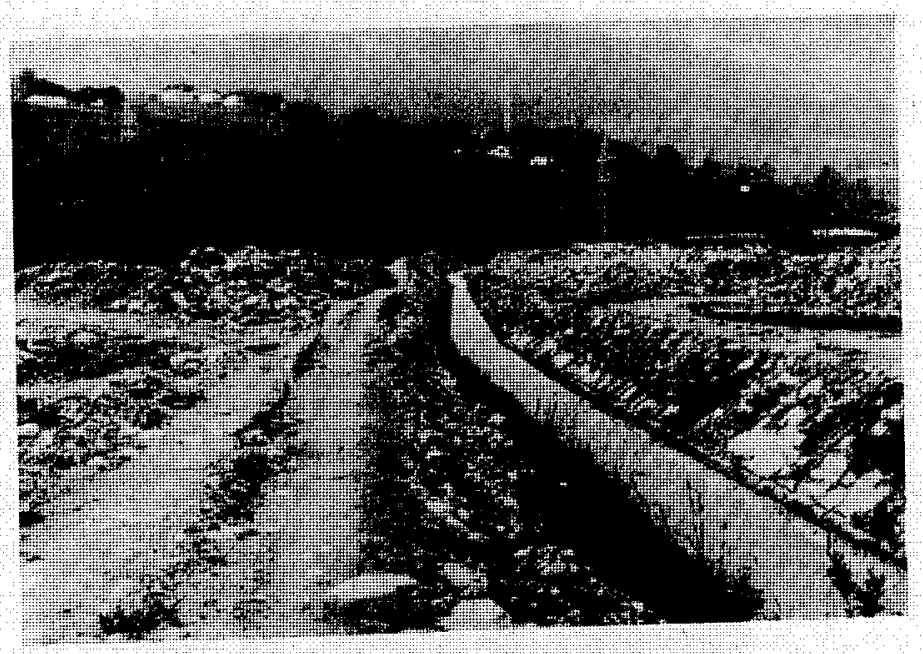

Fig. 5 - Debris blanket deposited by a debris flow (Niedernsill, Pinzgau, Austria).

From experiments, one finds for $\lambda \leqslant 12(c \geqslant 0.60)$ :

$$
\begin{aligned}
f(\lambda) & =\lambda \\
\alpha_{t} & =0.042 \\
\tan \alpha & =0.32
\end{aligned}
$$

and hence

$$
\begin{aligned}
& P=0.0400(\lambda D)^{2} \sigma\left(\frac{\mathrm{d} U}{\mathrm{~d} y}\right)^{2} \\
& T=0.0128(\lambda D)^{2} \sigma\left(\frac{\mathrm{d} U}{\mathrm{~d} y}\right)^{2}
\end{aligned}
$$


For the macro-viscous region, one has

$$
\begin{gathered}
T=\eta(1+\lambda)\left(1+\frac{1}{2} f^{\prime}(\lambda)\right) \mathrm{d} U / \mathrm{d} y \\
P=T \cot \alpha
\end{gathered}
$$

where $\eta$ is the viscosity and the other symbols have the previously described meaning. From experimental evidence one finds (Bagnold, 1956) in this case $f^{\prime}(\lambda)=\lambda$, tan $\alpha=0.75$ which yields

$$
\begin{gathered}
T=(1+\lambda)\left(1+\frac{1}{2} \lambda\right) \eta \mathrm{d} U / \mathrm{d} y \\
P=1.33 T
\end{gathered}
$$

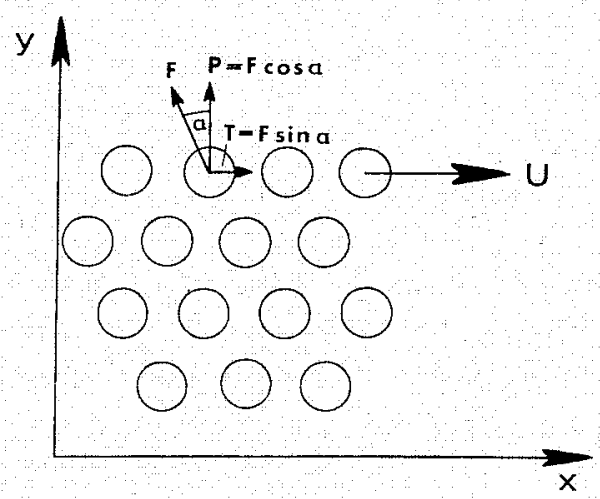

Fig. 6 - Force diagram in shearing grains leading to dispersive pressure (after Bagnold, 1954) $\left({ }^{2}\right)$.

The transition from inertial to macro-viscous regime occurs when the critical number $N$

$$
N=\frac{\lambda^{1 / 2} \sigma D^{2} \mathrm{~d} U / \mathrm{d} y}{\eta}
$$

has some value between 40 and 450 . For $N<40$ one has a macroviscous regime, for $N>450$ an inertial regime. The transition takes place in between these values of $N$. 
It is the dispersive pressure $P$ which counteracts gravity and thus holds a mixture of water and debris in a fluidized state. Here, at least, is a mechanism which can explain the phenomenon of suspension. In turbidity currents, the suspension is provided by the prevailing turbulence; in the "dispersive" flow case, by the grain collisions and the effect of neighbouring grains upon the viscous flow regime in their vicinity. Turbulence, if any is present, is rapidly damped away and has no effect in high grain concentrations.

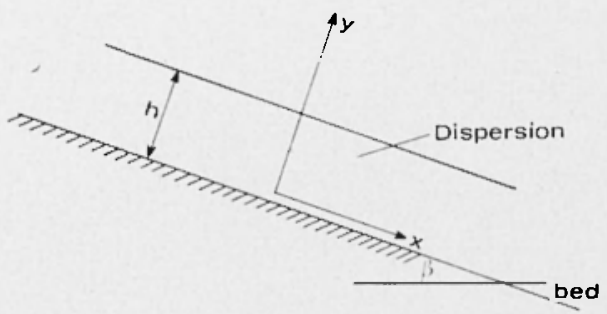

Fig. 7 - Geometry of the motion in a debris flow.

\section{4. - Application to Alpixe Debris Flows}

Any avocation of Bagnold's dispersive pressure as a possible mechanism of suspension and fluidization in Alpine debris flows must entail an analysis of the orders of magnitudes of the dynamical quantities involved.

The debris flow, accordingly, would encompass two types of materials: the continuous phase consisting of the water including the fine suspensions of viscosity $\eta$ and density $\varrho ;-$ and the dispersed phase consisting of the large debris of median diameter $D$, density $\sigma$ and volume concentration $c$.

Then, the motion occurs as sketched in Fig. 7 . The shearing stress $G$ parallel to the slope at distance $y$ above the bed, due to gravitational forces is

$$
G=[\varrho+(\sigma-\varrho) c] g(h-y) \sin \beta
$$

The dispersive pressure $P$ must overcome the underwater pressure $W$ of the grains

$$
W=(\sigma-\varrho) c g(h-y) \cos \beta
$$


Motion is possible if the ratio $G / W$ due to gravitational forces equals the ratio $T / P$ due to the dispersive stress. Thus

$$
\frac{T}{P}=\tan \alpha=\frac{G}{W}=\frac{\varrho+(\sigma-\varrho) c}{(\sigma-\varrho) c} \tan \beta
$$

Setting the shearing stress $T$ due to the dispersive stresses equal to that due to gravitational forces $G$ yields in the inertial regime

$$
0.0128 \sigma(\lambda D)^{2}\left(\frac{\mathrm{d} U}{\mathrm{~d} y}\right)^{2}=[\varrho+(\sigma-\varrho) c] g(h-y) \sin \beta
$$

and in the macro-viscous regime

$$
(1+\lambda)\left(1+\frac{\lambda}{2}\right) \eta \frac{\mathrm{d} U}{\mathrm{u} \ddot{y}}=[\varrho+(\sigma-\varrho) c] g(h-y) \sin \beta .
$$

This can be checked against the observations. We use $\underline{o}=\mathbf{1 . 6}$ $\mathrm{g} / \mathrm{cm}^{3}$ (of the basic slurry), $\sigma=3.0 \mathrm{~g} / \mathrm{cm}^{3}$ and $c=0.70$ i.e. $\lambda=53.4$. We obtain in the inertial range

$$
\begin{aligned}
& \left(\frac{(\mathrm{d} U}{\mathrm{d} y}\right)^{2}=\frac{\varrho+(\sigma-\varrho) c}{0.0128 \sigma} g(h-y) \sin \beta \frac{1}{(\lambda D)^{2}} \\
= & \frac{1}{(\lambda D)^{2}} \cdot \frac{\varrho+(\sigma-\varrho) c}{0.0128 \sigma} \cdot g(h-y) \sqrt{\frac{1}{1+\cot ^{2} \beta}} \\
= & \frac{\varrho+(\sigma-\varrho) c}{0.0128 \sigma} \cdot \frac{g(h-y)}{(\lambda D)^{2}}
\end{aligned}
$$

which yields with the values for $\varrho, \sigma$ and $c$ given above and tan $\alpha=0.32$ :

$$
\frac{\mathrm{d} U}{\mathrm{~d} y}=0.053 \frac{1 \bar{g}}{D}(h-y)^{1 / 2}
$$

At the surface, this yields for $U$ after integration

$$
U=0.0533 \frac{1 / \bar{g}}{\bar{L}} \frac{2}{3} h^{3 / 2}
$$


Let us take $h=3 \mathrm{~m}, D=10 \mathrm{~cm}, g=9.81 \mathrm{~m} / \mathrm{sec}^{2}$. Then one obtains for the surface velocity $U$

$$
U=5.78 \mathrm{~m} / \mathrm{sec}
$$

which shows that the range of velocities observed in nature certainly falls into the theoretical range.

One can check whether the flow regime is indeed the inertial one. The condition is given by

$$
N>450 .
$$

With the values found above one obtains

$$
N=\frac{366}{\eta}(300-y)^{1 / 2}
$$

The question, then, is to insert a reasonable value for the viscosity $\eta$. For water, $\eta=0.01 \mathrm{cgs}$ units; however, the viscosity is required not of the water but of the slurry of density $o=1.6 \mathrm{~g} / \mathrm{cm}^{3}$ which is supporting the coarse debris. It is difficult to make meaningful estimates of this viscosity, but since the fine material in the slurry moves essentially in suspension, its viscosity cannot be much greater than about one order of magnitude above that of water. Setting $\eta=0.5 \mathrm{cgs}$ yields

$$
N=732(300-y)^{1 / 2} .
$$

It turns out that

$$
N>450
$$

for $y<299.62 \mathrm{~cm}$. This indicates that the assumed flow regime is indeed realized over (almost) the whole depth of the flow.

Thus, the model of Alpine debris flows proposed here is a reasonable one. 


\section{REFERENCES}

(1) Aulitzk y H., 1970. - Der Enterbach am 26.7.1969. Wildbach- u. Lawinenverbau, Heft 34, S. 31-66.

(2) BAGNOLD R. A., 1954. - Experiments on a gravity free dispersion of large solid spheres in a Newtonian fuid under shear. "Proc. Roy. Soc. London", Ser. A., 225, p. 49-63.

${ }^{(3)}$ HoFmann F., 1972. - Die Hochwasserkatastrophen im Oberpinzgau in den Jahren 1970 und 1971. Wildbach- und Lawinenverbau, Sonderheft (März), p. 3.51.

(4) Scheidegger A. E., 1974. - Physical Aspects of Natural Catastrophes. Elsevier, Amsterdam.

(5) Stiny J., 1910. - Die Muren, Verlag der Wagner'schen Univ. Bibliothek, Innsbruck, p. 139. 